\title{
A KNOWLEDGE BASED PLATFORM TO SUPPORT INFORMAL LEARNING IN DO-IT-YOURSELF RETAIL STORES
}

\author{
Lukosch, Heide; De Vries, Pieter \\ Delft University of Technology, Netherlands \\ \{h.k.lukosch; pieter.devries\}@tudelft.nl
}

Keywords: Informal learning, social constructivism, Microtraining, media supported learning, workplace learning

Abstract: This paper is about an innovative approach to informal, workplace related learning in do-ityourself retail stores. Most organizations ignore informal learning as a strategic tool, although this kind of learning dominates the workplace in many organizations. The objective of the project described here was to facilitate informal learning practices by the sales people on the work floor with an easy to use knowledge platform. The platform should be structured in line with current learning concepts, the specific target group and organizational requirements. An existing knowledge platform was upgraded in this sense to better serve the informal learning activities using a semantic approach and Microtraining, a didactical concept for structuring short learning sessions. This platform has been tested in practice in the retail stores. The outcome of the project shows that using the knowledge platform can indeed strengthen the advisory services of the employees. The semantic web as well as the Microtraining approach enhanced the usability of the platform and fostered selfdirected learning, understood as an important component of informal learning practices.

\section{INTRODUCTION}

Most companies consider learning to take place predominantly within formal learning settings like classrooms, seminars and predefined online courses. In practice it shows that these settings lack the flexibility to deal with the fast changing learning demands of today's companies. More striking, most of the knowledge needed at the workplace is derived from informal learning activities like discussions between colleagues and information exchange with suppliers (Cross, 2007). Current research shows that the effect of formal and informal learning on organizational learning is positive, but a too dominant formal structure is counterproductive (Wenger, 1998; Janowicz-Panjaitan \& Noorderhaven, 2008). Therefore it seems reasonable to look for ways to support informal learning practices. Up till now, informal learning activities in organizations seem to be incidental, unstructured, lack control and appear to be difficult to integrate in every day's work as well as to monitor, evaluate and assess.

In this paper we describe a concept that has been developed to support informal learning practices in do-it-yourself (DIY) retail markets. The specific target group of the project was the sales people on the work floor in the stores. The main goal was to develop a support mechanism that would help the sales people to continuously update their product knowledge and to enhance their ability to deal with the demands of the customers. The outcome of the research project was the development of an online platform based on the analysis of the actual knowledge and learning processes in the retail stores and new technology supported educational concepts like the Microtraining method (Overschie, 2007; De Vries \& Brall, 2008). 
Important issues in the research project were the use and acceptance of the knowledge platform as a tool fostering informal learning by personnel and management in the DIY stores. The platform was applied at a number of do-it-yourself-markets in different regions in Germany. The implementation strategy contained an analysis of learning practices beforehand, which was used to set up the implementation trajectory using introductory sessions and a first evaluation of the use of the adapted knowledge platform. For the RELOAD platform, we used a technology already established within the DIY branch. This technology consisted of an e-learning platform containing formal courses that are required for new employees and apprentices. The former version was used because basic functionalities like log on and navigation parts are well known and familiar to the employees. On the other hand, this version of the learning platform did not ground on instructional design referring to informal learning, did not support communication and collaboration amongst the users and was not based on a semantic web. These are the most crucial points that were changed in the new knowledge platform. The first experiences show that the renewed knowledge platform is accepted as a central access-point to the knowledge needed for everyday tasks at work. In the following, we show the crucial aims of our research project, the theoretical background of the Microtraining method, the evaluation process and the first outcomes of the evaluation.

\section{THE RELOAD PROJECT}

The DIY market is a sector with a rapid changing flow of information on products, product change and innovation as well as product advertisement as crucial elements in the business processes. In practice employees and management are not very much used to value informal and computer supported learning (De Vries \& Leege 2008). This branch is dealing with employees who often come from other sectors with a less intense learning profile and who are not used to a greater variety of learning beyond the traditional settings. This is especially true for the group that can be defined as un-learned, older employees as well as novices that enter the sector. This group basically has to develop their knowledge and competences while being on the work floor. The existing courses hardly fit the particular learning needs of this group due to the very formal structure and timing and the lack of up to date information.

The RELOAD project focuses on the development of an e-learning approach that allows more workplace related information acquisition and informal learning. The core of the project is the development of an educationally structured online learning and knowledge platform based on a semantic network approach that allows interlinking and an easier access to the content. This knowledge platform is meant to foster media supported, informal and connected learning to enable the target group for timely and appropriate individual learning in line with workplace related requirements. New features that were added compared to the already existing system were: the development of different points of entry, like an encyclopaedia, a course listing of Microtraining, a 3-D house of applications, a product finder, a search option and personal learning desk. In this way different types of learning approaches were supported, like a quick information search or course based learning.

Next to the adaptation of the platform to the specific learning needs, Microtraining learning units have been developed, which are short 15 minutes, multimedia units that focus on workplace related issues and can easily be integrated in the daily working schedule. The specifications for these features were derived from an upfront analysis of the learning context in the DIY sector (De Vries \& Leege 2008) and the didactical concept developed in preparation of the functional design of the RELOAD concept.

The RELOAD project was supported by the Leonardo program of the European Union from 2007 to 2009. The platform is to be found at www.RELOAD.produktwissen.eu.

\section{NEW LEARNING CONCEPTS AND TOOLING}

The sales people in the DIY-markets spend most of their time on the shop floor where they meet the customers. Therefore it is rather difficult to organize long-term training activities. On the other hand, they do not have clients all the time and could use these 'gaps' in the sales activities for (short) learning sessions. Thus, the aim of our research is to foster informal learning that can take place in this context.

This understanding of the term 'informal learning' is very much based on the idea of where learning takes place. Nevertheless, the distinction between formal and informal is not seen as a strict separation between different learning activities. 
Formal education is understood as traditional, class and curriculum bounded and informal learning as a predominantly social activity consisting of a mix of learning related actions.

In reality we learn all the time, under different circumstances, but apparently more informal than formal. Cross (Cross, 2007) states that $80 \%$ of the knowledge we need for our work is obtained through informal processes, the remaining $20 \%$ through formal channels. Obviously this is not yet common ground for learning professionals, because about $80 \%$ of the training budget is spent on formal business training efforts. Thus, we are looking for a learning model that is able to support informal learning at the workplace, not necessarily replaces formal learning, but supplies an additional opportunity to increase the learning capacity close to the work floor.

The learning concepts that are based on socioconstructivist principles work well for informal, practical, ad-hoc-like, spontaneous learning (De Vries \& Brall, 2008). Core of the constructivist concept is the premise that we all have our own 'mental model' that is developed in interaction with the world around us (Vygotsky, 1978; Wertsch, 1987). The main principles are that each person is unique with regard to knowledge and experience; people primarily learn by actively trying and learning therefore is always related to a particular social context.

Not only active learning is important, learning should also be an activity directly linked to the daily work of the employees and to be accomplished in the workplace environment in collaboration with other colleagues. In this view, we understand learning at the workplace as collaborative knowledge creation. Not only knowledge is acquired, but also shared with others and within a social process new practices are developed (Tynjälä, 2008). In general, learning at the workplace can be characterized as creating new modes of action, new practices, new procedures and new products. Informal learning at the workplace means learning in collaboration with others, mostly with your own colleagues. Interaction between novices and experts is of crucial importance for that sort of learning activities (Tynjälä, 2008). Thus, we looked for a learning solution that would connect people with different levels of knowledge.

Assuming that people are unique learners, they also have a different experience level. According to Jonassen et al. (Jonassen, Mayes, McAleese, 1993; Jonassen, 1997) and Rosenberg (Rosenberg, 2006) this should be taken into account while designing learning activities. Three levels are distinguished: early development, competent and experienced, expert. A newcomer needs good formal and structured learning to acquire basic knowledge and skills in an appropriate fashion. More experienced employees with more knowledge and skills are better served with a largely informal learning situation that better fits the rather ad hoc learning needs, so common for workplace related learning. For people with expert knowledge and experiences, formal and structured learning can even become counter-productive, because it does not fit the very personal learning needs.

In the case of the DIY-branch this means that the already existing learning platform with e-learning courses works very well for newcomers, but for the experienced workers one need to rely much more on the self-initiative of the employee to support his or her learning process.

\section{MICROTRAINING}

Based on the above findings a didactical concept was developed for a renewed knowledge platform that was based on the learning concepts as discussed and the Microtraining approach as an overarching learning method and a structuring element for the courses in the RELOAD platform.

Microtraining is a method for structuring selflearning or group learning to develop learning materials, e-learning and other learning activities, while focusing on the applicability of what is learned and needed at the workplace (De Vries \& Brall 2008). It supports the development of short, customized learning sessions for different groups of employees with the focus on workplace related learning demands. It is in fact a framework for types of self-promoted learning support to be used by the employee or manager with a high level of practical relevance. A Microtraining arrangement comprises a time span of 15-20 minutes for each learning occasion, which can activate and maintain learning processes for a longer period if they are bundled up in series, being face-to-face, online or in an elearning situation. Each session starts actively, followed by a demonstration or exercise, feedback or short discussion, and ends with directions for further development and a brief preview of the next sessions.

In RELOAD, the didactical concept of Microtraining was used to develop learning units within the learning platform. The focus of the learning units is on work related issues crucial for the daily work in the DIY-stores, such as product knowledge, customer relationship and sale strategies. The Microtraining method is not only meant to be used as a format to develop ready-made (electronic) learning units, but to familiarize the 
learners with the didactical format to apply this in informal learning settings for better results. The time limit of the learning units is a crucial point for the effective use on the work floor, but not the only one. Microtraining is meant to be used by a group of learners in relation to their work floor related learning demands that supplies solutions and a strategy for the reuse of these solutions. Furthermore, the structure of the Microtraining sessions is easy to understand and flexible. It can be applied to any new topic arising, so that companies are able to develop their own learning materials on basis of the Microtraining concept.

\section{EVALUATION PROCESS AND FIRST RESULTS}

To match the theoretical considerations with the actual requirements of the DIY markets, we developed an evaluation plan based on the Corporate (e-) Learning Strategy (CLS) model (De Vries, 2005). This model is marked by a holistic approach and subsequent phases for the development of a sustainable learning strategy. This allows the development of a clear picture of the actual situation at both the strategic, tactical and operational level of an organization.

The first evaluation amongst the management and employees showed a high workload of the employees. They have to perform and support the company's high quality level advisory process including a rather demanding communication with the clients and an ongoing need for product information. Furthermore, the fluctuation of employees, typically for the branch, means a lot of pressure for the workers in the markets. Understaffing means a higher workload and less time for information acquisition and explicit learning activities. The on-going product changes and the fact that well-informed customers are becoming the typical DIY customer require wellbalanced information and learning strategy. The rivalry is harsh between the competitors on the DIY market. The needs analyses showed that competitive advantage must be achieved by the ability to process the increasing information flux. The access to up to date information and the ability to process this information is a challenge for media novices, like most employees of the DIY-markets. Suppliers are considered an important source of information. They convey important information to the markets using seminars and different media like websites, trainings, and leaflets, learning platforms, courses and games. The evaluation shows that these resources are hardly used by the target group. In addition most suppliers use different information channels and media, which makes it rather difficult for the employee to find the right information and use it correctly.

\section{SYSTEMS REQUIREMENTS AND APPROACH}

The theoretical findings and the outcome of the evaluation lead to a specification of the requirements for the knowledge platform. Taking into account that the new knowledge platform has to be based on the previous findings and the didactical concept, employees have to be able to easily execute the learning activities by themselves. A list of system requirements for the learning concept emerged, including the applicability of learning activities in the daily work processes, a time-related maximum of learning activities, flexibility of content, cost effectiveness and integration of information from the suppliers of the markets.

As an answer to the crucial need of active learning, we realized different learning approaches within the new system architecture, to make intuitive execution of learning activities for different kinds of learners possible. The knowledge platform now contains an encyclopaedia, short Microtraining courses, a 3-D house of applications, a product finder and a search engine. Furthermore, users are able to personalize the system by using a personal desktop (see figure 1).

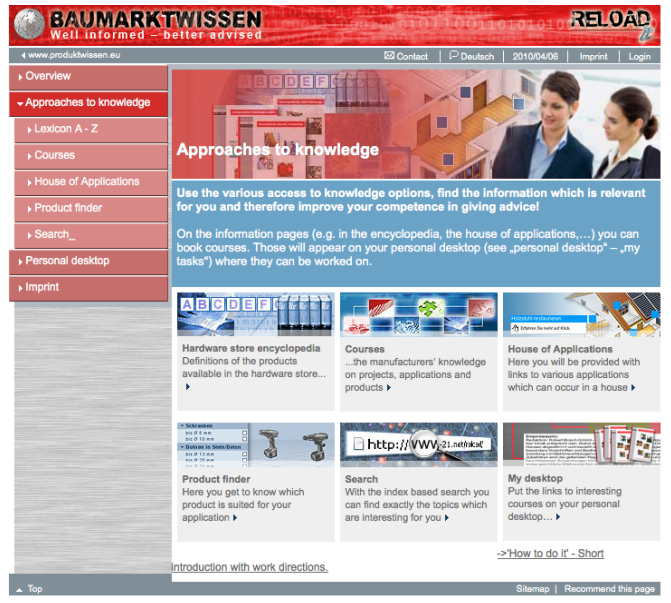

Figure 1: Different access ways to knowledge with the RELOAD-platform.

The encyclopaedia included in the platform stores alphabetically ordered knowledge about (new) 
products and other hardware that is been sold in DIY-markets. This offers a very easy and quick access to knowledge about single tools and products. The course-area contains a large amount of short learning units, offering information from the suppliers. The courses are also alphabetically ordered, and a short description as well as further information is available. With this overview, the best learning activity to a recent problem is easily to be found. The house of applications offers thematically access to knowledge by showing a 3-D model of a house with different workspaces, which fulfils the requirement that the knowledge included is applicable to different daily work tasks. (see figure 2).

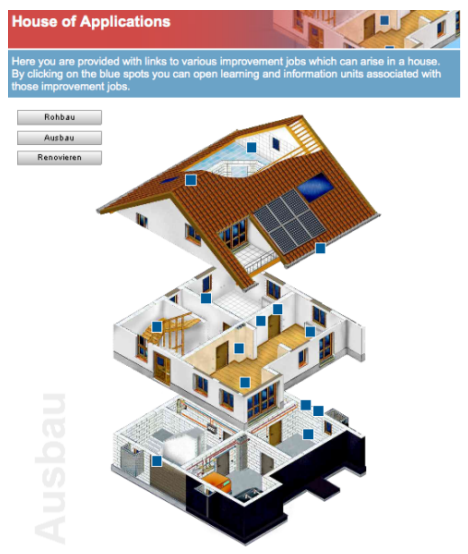

Figure 2: House of applications to offer work-related access to knowledge.

If one wants to use the traditional approach of a search engine, this is possible with the RELOAD platform, too. A term can be searched within whole documents, a title or a web address. Platform wide, the search can include encyclopaedia entries, courses and links to information of the suppliers. With the use of the personal desk, a user is able to save links and courses he or she is interested in or has already visited. So a personalized knowledge landscape can be build.

Within these various approaches, different content is accessible. The user can enter a short learning course, or he or she can pick up some short information about projects or products. The multidimensional learning approach offers the opportunity to use different scenarios. Firstly, the information offered by the platform can be used for preparation and for reviewing the sales-customer relationships. Secondly, it can be used for training purposes organized by management. The executive can decide to use Microtraining for one (group) of employees. With the didactical approach of
Microtraining and the use of the learning system, it is possible to execute on-the-job-training for new product assortments, use information as addition/preparation for face-to-face-trainings, develop an introduction for new products/actions and to carry out safety trainings, point-of-sale, inventory. Thirdly, employees are able to develop their own Microtraining learning units on the basis of new learning demands and newly acquired knowledge, for example after a product training by a supplier.

\section{Experiences}

A first pilot phase was executed and evaluated during the RELOAD project. A group of 18 test persons was chosen and their use of the knowledge platform was reported. After using the system, interviews were held with the test persons. The first experiences with the knowledge system showed that some of the employees had difficulties to access the system due to a lack of hardware devices in the markets itself. Learning and training was not part of the business plan dealing with questions of learning policy, learning time and space. Despite that, a group of test persons used the platform at home and considered this information source as useful, but the project's goal to support learning at the workplace was not realized with this mode of use. Additionally, the use of the platform was not part of any training sessions, which made it a problem for some of the employees who were not used to learning systems supporting self-directed learning.

Furthermore, the interviews showed that the content and amount of content of the platform was very important for its usefulness and attractiveness. The learning units and information already obtainable were judged as very useful in daily work contexts. It was reported as positive that up-to-date information from the suppliers was included. The possibility to have one access point to the information needed at the workplace was very much appreciated. The introductory session of the new learning method was received positively. Asked about the kind of information resources the employees want to use when being in need of actual information, the answers were varied ranging from unstructured information, self-directed learning, small information pieces from time to time to classroom-learning or using the internet at work. Thus, a flexible solution with different access modes as the developed RELOAD-platform seems to be an answer to these heterogeneous learning needs. 


\section{Conclusions}

With the new platform developed within the RELOAD project easy and direct access to actual knowledge at the workplace is enabled. The new knowledge platform offers unique knowledge by integrating exclusive information from suppliers and markets. With the possibility to personalize the learning activities, it shows a reasonable combination with other trainings. For the employees with ample time for learning and training, the use of the Microtraining method means that an active start for learning is fostered by the system itself. It allows the structuring of the knowledge through an efficient and goal-oriented learning structure. The learning activities itself are flexible regarding time, duration, frequency, and content. The interactive approach improves the active use of the acquired knowledge and the sharing of knowledge. Our evaluation showed that work appreciation is improved concerning communication and learning.

Nonetheless, with the knowledge platform, both informal and formal learning can be supported. The underlying method can be used online, face-to-face or in blended learning scenarios. The outcomes of our research project show that the advisory services of the employees of this branch can be strengthened with the use of a knowledge platform. The introduction of the new, informal learning method, the level of usability as well as the amount of accessible content of the knowledge platform, seem to be the most important points for the success of such a platform.

In summary, it showed that the method chosen is able to foster active, informal learning at the work place, but that the success of the learning platform strongly relates to experiences of learners, content of the platform and technical facilities on the work floor. Next steps to be taken are a quantitative evaluation with end-users to analyse the use of the system and to improve the platform and the learning approach of the Microtraining method based on the new findings. A crucial question within this evaluation will be how learners experience the use of the platform as a medium for knowledge sharing.

\section{REFERENCES}

Cross, J., 2007. Informal Learning: Rediscovering the Natural Pathways that Inspire Innovation and Performance. Pfeiffer, San Francisco.

De Vries, P., 2005. An Analysis Framework Approach for Managing Corporate E-learning Development. Brussels: De Vries. Doctoral dissertation.
De Vries, P. \& Brall, S., 2008. Microtraining as a Support Mechanism for Informal Learning. In: eLearning Papers $\mathrm{N}^{\circ} 11$, November 2008 , pp. 1-9.

De Vries, P. \& Leege. T., 2008. Final Report WP 1: Baumärkte und Lernen: eine Bedarfsanalyse. RELOAD project. DE/07/LLP-LdV/TOI/147058. Leonardo Project European Union.

De Vries, P. \& Lukosch, H., 2009. Supporting Informal Learning at the Workplace. In IJAC, International Journal of Advanced Corporate Learning, on: ww.ijac.org, (International E-Learning Association/International Association of Online Engineering).

Granovetter, Mark, 1983. The Strength of Weak Ties: A Network Theory Revisited. Sociological Theory, Vol. 1, pp. 201-233.

Janowicz-Panjaitan, M./Noorderhaven, N., 2008. Formal and informal interorganizational learning within strategic alliances, in: Research Policy Volume 37, Issue 8, September 2008, pp 1337-1355.

Jonassen, D., Mayes, T., \& McAleese, R., 1993. A manifesto for a constructivist approach to uses of technology in higher education. In T.M. Duffy, J. Lowyck, \& D.H. Jonassen (Eds.), Designing environments for constructive learning (pp. 231-247), Heidelberg.

Jonassen, D. H., 1997. Instructional Design Models for Well-Structured and Ill-Structured Problem-Solving Learning Outcomes. In: Educational Technology Research and Development 45 (1): 65-94.

Lukosch, H. \& De Vries, P., 2009. Mechanisms to support Informal Learning at the Workplace. In: Proceedings of ICELW'09, The International Conference on ELearning at the Workplace. New York.

Overschie, M., 2007. Microteaching Manual: Effective transfer of knowledge for Sustainable Technological Innovation. On http://www.microteaching.org.

Rosenberg, Marc, 2006. Beyond E-Learning. Approaches and Technologies to enhance Organizational Knowledge, Learning, and Performance. Pfeiffer.

Siemens, G., 2005. Connectivism: A Learning Theory for the Digital Age. International Journal of Instructional Technology and Distance Learning, Vol. 2, No 1.

Siemens, G., 2006. Knowing Knowledge. Lulu Publishers (www.lulu.com).

Tynjälä, P., 2008. Perspectives into learning at the workplace. In: Educational Research Review Volume 3, Issue 2, 2008, pp 130-154.

Vygotsky, L.S., 1978. Mind and society: The development of higher mental processes, Cambridge, MA.

Weistra, H., 2005. Leerenergie en de voorwaarden voor (in) formeel leren. In: Opleiding en Ontwikkeling. Oct. 2005, pp 17-21.

Wenger, E., 1998. 'Communities of Practice. Learning as a social system', Systems Thinker, http://www.co-i1.com/coil/knowledge-garden/cop/lss.shtml.

Wertsch, James V., 1987. Vygotski and the formation of the mind. Cambridge. 